\title{
COMUNICAÇÃO
}

\section{ANÁlISE COMPARATIVA DOS CUSTOS DE PRODUÇÃO DE DUAS PROPRIEDADES LEITEIRAS, NO MUNICÍPIO DE UNAÍ-MG, NO PERÍODO DE 2003 E 2004}

\author{
Comparative analysis of production cost of two dairy farm, in the city \\ of Unaí - MG, in the period of 2003 and 2004 \\ Francisval de Melo Carvalho1, Érika Oliveira Ramos², Marcos Aurélio Lopes ${ }^{3}$
}

\begin{abstract}
RESUMO
Objetivou-se, neste estudo comparar os custos de produção do leite de duas propriedades localizadas no município de Unaí Minas Gerais, e a influência deles na lucratividade. Trata-se de um estudo de dois casos, cujos dados foram extraídos de planilhas de análise técnico-gerencial das propriedades, nos anos de 2003 e 2004. Observou-se uma diferença entre os custos apurados, principalmente em função do nível tecnológico adotado. Pôde-se concluir que o aumento de escala de produção diluiu os custos fixos da atividade, diminuindo o custo total e aumentando as margens; que o uso de tecnologias viáveis possibilita uma melhor resposta do sistema a diversos fatores de produção, permitindo uma adaptação mais rápida, o que influenciará no retorno financeiro. Concluiu-se também que, nas condições estudadas, não é possível definir o melhor sistema, pois os fatores de produção são diferentes.
\end{abstract}

Termos para indexação: Administração rural, análise de rentabilidade, atividade leiteira, custo de produção.

\section{ABSTRACT}

The objective of this study was to compare the production costs and their influence on the profitability of two dairy farms, located in the city of Unaí - MG, Brazil. Two cases were studied, where one used data technical and managerial control of the farm. One verified a difference among the observed costs, mainly due to the adopted technology. One may conclude that the increase of production scale reduces the fixed costs of the activity, decreasing the total cost and increasing the profits and that the use of viable technology enables a better answer of the system to several production factors, reaching a faster adaptation, influencing the finantial return. It may also conclude that it isn't possible to define the best system in the studied conditions, since the production factors are different.

Index terms: Dairy cattle, production cost, profitability analysis.

\section{(Recebido em 12 de dezembro de 2006 e aprovado em 25 de março de 2008)}

Diversas transformações, dentre outros fatos, têm contribuído para que os produtores de leite reflitam sobre a necessidade de administrarem bem a atividade, tornandose mais eficientes e, conseqüentemente, competitivos. Nessa nova realidade, ter controle adequado e, principalmente possuir um sistema de custo de produção de leite, que gere informações para a tomada de decisões rápidas e objetivas são fundamentais para o sucesso da empresa (LOPES et al., 2004a).

O custo de produção é um instrumento necessário para o administrador da atividade leiteira. Entretanto, seu cálculo envolve algumas questões simples, outras nem tanto, razão pela qual seu uso é pouco praticado Gomes (2000).
Os dados obtidos da apuração dos custos de produção têm sido utilizados para diferentes finalidades, como: estudo da rentabilidade da atividade leiteira; redução dos custos controláveis; planejamento e controle das operações do sistema de produção do leite; identificação e determinação da rentabilidade do produto; identificação do ponto de equilíbrio do sistema de produção de leite; e instrumento de apoio ao produtor no processo de tomada de decisões seguras e corretas (LOPES \& CARVALHO, 2000). Dados de custo de produção têm sido utilizados também para cálculo dos valores econômicos para características de gado de leite (BUENO et al., 2004; MADALENA, 2000; MARTINS et al., 2003), bem como

1Doutor em Administração de Empresas, Professor - Departamento de Administração de Economia/DAE - Universidade Federal de Lavras/UFLA Cx. P. 3037 - 37200-000 - Lavras, MG - francarv@ufla.br

${ }^{2}$ Administradora, Especialista em Gestão do Agronegócio - Rua Patos de Minas, 496 - Nova Divinéia - 38618-000 - Unaí, MG

${ }^{3}$ Doutor em Zootecnia, Professor - Departamento Medicina Veterinária/DMV - Universidade Federal de Lavras/UFLA - Cx. P. 3037 - $37200-000$ Lavras, MG - malopes@ufla.br 
para quantificar ineficiências econômicas (BRAVO-URETA \& RIEGER 1991; GOMES et al., 1989; KUMBHAKAR et al., 1989; TUPY \& YAMAGUCHI, 2002).

A necessidade de analisar-se economicamente a atividade leiteira é importante, pois, através dela, o produtor passa a conhecer e utilizar, de maneira inteligente e econômica, os fatores de produção (terra, trabalho e capital). A partir daí, localizam-se os pontos de estrangulamento para depois concentrar esforços gerenciais e ou tecnológicos, para obter sucesso na atividade e atingir os objetivos de maximização de lucros ou minimização de custos (LOPES \& CARVALHO, 2000). De acordo com Reis et al. (2001), por não conseguir controlar o preço do produto que vende, o produtor necessita administrar as variáveis que estão sob o seu controle. Trata-se de uma estratégia para tornar seu produto competitivo, atingindo menores custos de produção. O resultado econômico, em um mercado caracterizado pela concorrência, depende do gerenciamento dos custos de produção do leite e dos ganhos de escala.

Objetivou-se, neste estudo comparar os custos de produção em duas propriedades rurais produtoras de leite, localizadas no município de Unaí - Minas Gerais, e analisar a influência deles na lucratividade.

Este trabalho foi direcionado para o estudo dos valores que compõem-se o custo de produção de duas propriedades produtoras de leite, na região de Unaí Minas Gerais e a influência dos custos de produção na lucratividade. $\mathrm{O}$ método de trabalho utilizado nesta pesquisa foi à aplicação do estudo de caso, visto ser o mais recomendado quando se pretende estudar a unidade com mais profundidade.

As duas propriedades, objeto deste estudo, foram escolhidas por participarem do projeto EDUCAMPO (projeto do Sebrae-Minas em convênio com a Cooperativa Agropecuária de Unaí - Capul), serem acompanhadas pelo mesmo técnico, participarem da mesma cooperativa, terem obtido em 2003 um lucro total muito semelhante, apesar de utilizarem sistemas de produção diferentes e, em 2004 apresentarem uma situação diferente, com um aumento de produtividade expressivo em uma das propriedades estudadas. Nas duas propriedades, os animais são manejados em sistema de pastagem no período das águas e confinados no período da seca.

Utilizou-se a metodologia de Custo de Produção, utilizada pela Universidade Federal de Viçosa - UFV em parceria com o SEBRAE-MG, que criaram o Programa de Gerenciamento do Custo de Produção do Leite - PCC Leite, também utilizado nas fazendas analisadas.
Os dados obtidos foram coletados por meio de planilhas e informações do técnico que presta assistência às fazendas, informações do proprietário e visita à propriedade. Esses foram organizados, selecionados os itens necessários e comparados com os dados da outra propriedade. O período de análise foi de vinte e quatro meses, dividido em dois períodos de doze meses, sendo que o primeiro período engloba os meses de dezembro de 2002 a novembro de 2003 e o segundo período de dezembro de 2003 a novembro de 2004.

Os recursos utilizados pelas propriedades, para a atividade leiteira, são os discriminados nas Tabelas 1, 2, e 3. A estruturação dos rebanhos está descrita na Tabela 4.

O rebanho da fazenda A constitui-se de animais girolandas, com grau de sangue variando entre o 3/4 e 15/ 16 holandês. A fazenda B possui rebanho constituído por animais da raça girolanda e gruzolanda, com grau de sangue entre o 1/2 e o 3/4 e ainda algumas vacas da raça gir e touro guzerá. O rebanho é constituído por animais nas seguintes proporções de raça: $25 \%$ de $1 / 2$ sangue girolandas e guzolandas, $50 \%$ sendo 3/4 girolandas e guzolandas e 25 $\%$ sendo $7 / 8$ girolandas. São animais de grande rusticidade, que foram totalmente gerados na propriedade, através de touros holandeses PO e principalmente através da inseminação artificial.

A propriedade A possui um rebanho mais especializado, precisando de uma maior quantidade de concentrado e de melhor qualidade de volumoso. $\mathrm{O}$ uso de concentrado sai do padrão geral de $3: 1$ (01 kg de concentrado para $3 \mathrm{~kg}$ de leite produzido) e vai até o 2,5:1, dependendo da fase de lactação. Na Fazenda B, o concentrado é fornecido, no período das águas, na base de $1 \mathrm{~kg}$ de concentrado para 3,5 $\mathrm{kg}$ de leite produzido e no período da seca na relação de $1 \mathrm{~kg}$ de concentrado para $3 \mathrm{~kg}$ de leite produzido, fazendo distinção da relação concentrado: leite entre os lotes de produção. As áreas utilizadas, bem como o seu uso estão descritas na Tabela 3.

Tabela 1 - Inventário de recursos utilizado para a pecuária leiteira.

\begin{tabular}{lcc}
\hline \multicolumn{1}{c}{ Discriminação } & Fazenda A & Fazenda B \\
\hline $\begin{array}{l}\text { Valor da total da } \\
\text { terra nua (R\$) }\end{array}$ & $646.250,00$ & $221.000,00$ \\
$\begin{array}{l}\text { Rebanho (R\$) } \\
\text { Máquinas e }\end{array}$ & $309.900,00$ & $280.400,00$ \\
$\begin{array}{l}\text { equipamentos (R\$) } \\
\text { Benfeitorias (R\$) }\end{array}$ & $165.046,98$ & $114.315,00$ \\
$\begin{array}{l}\text { Total do } \\
\text { Inventário (R\$) }\end{array}$ & $1.238 .023,980$ & $106.200,00$ \\
\hline
\end{tabular}


A mão-de-obra da fazenda A é composta por cinco funcionários, distribuídos da seguinte maneira: dois funcionários na ordenha dos animais, na limpeza das instalações e inseminação artificial; um, no trato dos bezerros e serviços gerais; um, na alimentação de vacas em lactação; e um funcionário para alimentação de vacas secas e animais de recria. A fazenda B possui três funcionários de maneira permanente, sendo que, na época da seca, contratam-se dois funcionários para auxiliar na alimentação do rebanho. As propriedades são administradas pelos proprietários, que residem na fazenda.
No cálculo do custo de produção de leite das propriedades estudadas, são separados os gastos com a produção de leite e com a criação de bezerras e recria de novilhas. Da mesma forma, contabilizou-se separadamente a renda bruta proveniente do leite e da venda de animais.

A Tabela 5 indica distribuição dos custos porcentualmente das duas propriedades, no período estudado, de 2003 e 2004. Percebe-se que poucos itens são responsáveis pela maior parcela dos custos: concentrado, silagem e mão-de-obra. Resultados semelhantes foram obtidos por Lopes et al. (2004b).

Tabela 2 - Benfeitorias utilizadas para a pecuária leiteira.

\begin{tabular}{lccc}
\multicolumn{1}{c}{ Fazenda A } & Valor $(\mathrm{R} \$)$ & Fazenda B & Valor $(\mathrm{R} \$)$ \\
\hline 01 Estábulo: & $30.000,00$ & 01 Estábulo: & $15.000,00$ \\
01 Curral: & $15.000,00$ & 01 Curral: & $15.000,00$ \\
01 Sala de ordenha: & $15.000,00$ & 01 Sala de ordenha: & $10.000,00$ \\
01 Cobertura para manejo: & 500,00 & 01 cobertura para manejo: & 5000,00 \\
13 Bezerreiro individual: & $1.690,00$ & 01 Bezerreiro coletivo: & 200,00 \\
01 Depósito para ração: & $2.500,00$ & 01 Depósito para ração: & $3.000,00$ \\
01 Sala de máquina: & $1.500,00$ & 01 Sala de máquina: & $2.000,00$ \\
6 Cercas Perimetrais: & $7.950,00$ & 10 Cercas Perimetrais: & $19.000,00$ \\
4 Cercas Internas: & $5.300,00$ & 10 Cercas Internas: & $3.000,00$ \\
Energia Elétrica: & $10.000,00$ & Energia Elétrica: & $10.000,00$ \\
2 Açudes: & $2.400,00$ & Sistema de água: & $6.000,00$ \\
Instalações tanque expansão: & $2.000,00$ & Instalações tanque expansão: & $3.000,00$ \\
02 Casa Colonos: & $6.000,00$ & 03 Casa Colonos: & $9.000,00$ \\
01 Silo Graneleiro: & $2.487,00$ & 01 Silo Graneleiro: & $1.500,00$ \\
05 Bebedouros: & $4.000,00$ & Tronco: & $2.000,00$ \\
01 Esterqueira: & $6.000,00$ & Silo: & $2.000,00$ \\
Cocheiras: & $2.500,00$ & & \\
Tronco: & $2.000,00$ & & \\
\hline Valor Total (R $\$):$ & $116.827,00$ & & $106.200,00$
\end{tabular}

Tabela 3 - Especificação da terra utilizada para a pecuária leiteira.

\begin{tabular}{lccc}
\hline \multicolumn{1}{c}{ Fazenda A } & Área (ha) & Fazenda B & Área (ha) \\
\hline Pasto brachiária & 250,00 & Brachiarão & 70,00 \\
Tifton & 1,00 & Andropogon & 41,00 \\
Canavial & 6,00 & Tanzânia & 10,00 \\
Capineira & 3,00 & Brachiaria & 60,00 \\
Silagem de milho & 20,00 & Canavial & 6,00 \\
Silagem de sorgo & 30,00 & Silagem de milho & 24,00 \\
Matas e reservas & 30,00 & Plantio direto & 10,00 \\
Gado Nelore & 110,00 & & 221,00 \\
Área total para leite & 310,00 & Área total para leite & 221,00 \\
\hline Área da propriedade & 450,00 & & \\
\hline
\end{tabular}


Tabela 4 - Rebanho utilizado para a pecuária leiteira.

\begin{tabular}{lcc}
\hline \multicolumn{1}{c}{ Categoria animal } & Fazenda A & Fazenda B \\
\hline Reprodutor & 02 & 02 \\
Vacas em lactação & 143 & 116 \\
Vacas secas & 13 & 55 \\
Novilhas em reprodução & 40 & 22 \\
Novilhas em recria & 63 & 61 \\
Bezerras em aleitamento & 21 & 30 \\
\hline
\end{tabular}

Tabela 5 - Porcentuais de participação no custo operacional efetivo

\begin{tabular}{lcccc}
\hline Componentes do custos de produção & \multicolumn{2}{c}{2003} & \multicolumn{2}{c}{2004} \\
\hline & Fazenda A & Fazenda B & Fazenda A & Fazenda B \\
\cline { 2 - 5 } Mão-de-obra & 6,82 & 11,25 & 8,15 & 7,66 \\
Manutenção de pastagens & 0,80 & 0,51 & 9,20 & 1,01 \\
Manutenção de canavial & 0,36 & 0,90 & 0,07 & 0,00 \\
Silagem & 12,38 & 13,54 & 6,76 & 18,24 \\
Concentrado e minerais & 55,19 & 45,59 & 55,20 & 48,36 \\
Medicamentos & 3,46 & 4,95 & 3,28 & 6,13 \\
Inseminação artificial & 1,72 & 1,28 & 0,84 & 1,04 \\
Transporte do leite & 6,56 & 8,22 & 1,83 & 2,94 \\
Energia e combustível & 4,40 & 5,63 & 4,34 & 4,80 \\
Impostos e taxas & 4,19 & 5,03 & 3,79 & 4,83 \\
Reparos & 2,01 & 1,78 & 4,57 & 3,30 \\
Outros custos & 2,11 & 1,32 & 1,97 & 1,69 \\
\hline \multicolumn{1}{c}{ Total } & $100 \%$ & $100 \%$ & $100 \%$ & $100 \%$ \\
\hline
\end{tabular}

A avaliação de porcentagens, como na Tabela 5, deve ser feita com cuidado, pois um valor depende do outro. Se, por exemplo, o custo de concentrado for muito elevado, pode reduzir a participação porcentual dos demais custos. Isso não quer dizer que os demais custos sejam baixos; podem até ser elevados em comparação com determinados padrões, o que distorce a análise. Dessa forma, deve-se, além dos porcentuais, avaliar os custos em valor absoluto.

Com os dados gerenciais apresentados na Tabela 6, fez-se uma análise nos dois períodos distintos, o ano de 2003 e 2004. Devido às características de cada propriedade e o sistema de produção adotado, ao se compararem os indicadores de produção do ano de 2003, percebe-se que apesar do lucro total serem semelhantes e do maior volume produzido nesse período pela fazenda A, a fazenda B, foi mais eficiente, pois teve um custo operacional efetivo unitário $25 \%$ menor e uma margem líquida unitária maior em $32 \%$ que a Fazenda A.

No ano de 2004, as propriedades mantiveram o mesmo sistema de produção. A Fazenda A teve um aumento de produção em $34,37 \%$, em virtude do sistema especializado e intensificado, empregado na propriedade nos últimos anos. Não houve compra de animais, apenas o crescimento natural, aumentou a produtividade por vaca e o custo operacional efetivo por litro de leite manteve a média de R \$ 0,37, como no ano anterior. Com esse aumento de produção e conseqüentemente diluição dos custos fixos, houve um acréscimo de $25 \%$ de margem líquida unitária, passando de $\mathrm{R} \$ 0,1265$ centavos por litro de leite para $\mathrm{R} \$ 0,1581$. A propriedade B teve um aumento de apenas $10 \%$ na sua produção, apesar do crescimento natural do rebanho, as médias de produção por vacas diminuíram, pois reduziu a alimentação das vacas devido a um problema que a propriedade teve com a silagem. O custo operacional efetivo, por litro de leite, teve um aumento de $15 \%$, passando de $\mathrm{R} \$ 0,29$ para $\mathrm{R} \$ 0,34$, afetando no valor da margem líquida unitária e aumentando apenas em 3,60\% o lucro total.

A análise comparativa das duas propriedades estudadas, Fazenda A e B, pertencentes à mesma região geográfica e acompanhadas pelo mesmo técnico, são exemplos de que, na atividade leiteira, nenhum sistema de produção é o melhor ou o mais adequado a todas as propriedades e que alguns fatores, previsíveis ou não, são determinantes para o crescimento e lucratividade da empresa rural. 
Independente do sistema de produção que se utiliza, o produtor sempre busca o lucro, seja reduzindo custos, aumentando a escala, trabalhando com vacas de maior produção ou utilizando sistemas mais rústicos. Qualquer que seja o sistema a ser utilizado, o produtor tem que definir primeiramente seus objetivos a curto e médio prazo e quais os recursos disponíveis. Após estar na atividade, essa análise tem que ser continuamente refeita, juntamente com as análises técnicas e financeiras e simulações de diversas situações produtivas para a tomada de decisões. A cada evento não previsto, o planejamento deve ser revisto.

As propriedades no primeiro período analisado são lucrativas, com taxas de retorno sobre o capital investido satisfatórias, já que o mercado utiliza hoje o padrão de $6 \%$ ao ano, que é a remuneração da caderneta de poupança como parâmetro sobre a viabilidade ou não do negócio, e as propriedades estavam com taxas em torno de $19 \%$ a.a. São propriedades que estavam crescendo, buscando o melhoramento técnico e gerencial.

Os dados do ano de 2003 indicam que as Fazendas A e B, apesar de terem produção em quantidades e custos diferentes, apresentaram pequena diferença em relação ao seu lucro total. Isso se justifica, pois a Fazenda A, mesmo com uma produção de 500 litros/dia a mais, não conseguia diluir os seus custos, que são maiores devido a um sistema de produção mais tecnificado que a Fazenda B.

Tabela 6 - Custo de Produção - Indicadores

\begin{tabular}{|c|c|c|c|c|}
\hline & \multicolumn{2}{|c|}{2003} & \multicolumn{2}{|c|}{2004} \\
\hline & Fazenda A & Fazenda B & Fazenda A & Fazenda B \\
\hline 1. Produção anual de leite (litros/ano) & $691.051,00$ & $506.217,00$ & $928.590,00$ & $556.487,00$ \\
\hline 2. Produção média de leite/dia & $1.893,29$ & $1.386,90$ & $2.544,08$ & $1.524,62$ \\
\hline 3. Vacas em Lactação (média/mês).(Cab./mês) & 115,25 & 102,58 & 132 & 120,08 \\
\hline 4. Total de Vacas (média/mês) . (Cab./mês) & 142,88 & 161,38 & 156,17 & 173,50 \\
\hline 5. Vacas em Lactação/Total de Vacas $(3 \div 4)$ & $80,66 \%$ & $63,57 \%$ & $84,53 \%$ & 69,215 \\
\hline 6. Produção / Vaca em lactação (Litros/dia) & 16,43 & 13,52 & 19,28 & 12,70 \\
\hline 7. Renda Bruta do Leite $(\mathrm{R} \$$ ) & $374.585,55$ & $274.088,53$ & $527.604,92$ & $308.321,09$ \\
\hline 8. Preço médio do Leite ( $\mathrm{R} \$$ litro) & 0,5421 & 0,5414 & 0,5680 & 0,5540 \\
\hline 9. Custo Operacional Efetivo do Leite (COE) & $255.208,43$ & $150.219,63$ & $341.170,99$ & $190.738,45$ \\
\hline 10. Custo Operacional Total do Leite (COT) & $287.103,80$ & $189.643,74$ & $380.776,43$ & $224.083,03$ \\
\hline 11. Custo Total do Leite (CT) & $319.641,35$ & $220.172,82$ & $417.089,94$ & $252.459,67$ \\
\hline 12. Custo Operacional Efetivo Leite (R $\$ /$ litro) & 0,3693 & 0,2967 & 0,3673 & 0,3428 \\
\hline 13. Custo Operac. Total do Leite (R $\$ /$ litro) & 0,4155 & 0,3746 & 0,4100 & 0,4027 \\
\hline 14. Custo total do Leite (R $\$ /$ litro) & 0,4625 & 0,4349 & 0,4491 & 0,4537 \\
\hline 15. COE do Leite / Preço do Leite $(12 \div 8)$ & $68,13 \%$ & $54,81 \%$ & $64,66 \%$ & $61,86 \%$ \\
\hline 16. COT do Leite / Preço do Leite $(13 \div 8)$ & $76,65 \%$ & $69,19 \%$ & $72,17 \%$ & $72,68 \%$ \\
\hline 17. CT do Leite / Preço do Leite $(14 \div 8)$ & $85,33 \%$ & $80,33 \%$ & $79,05 \%$ & $81,88 \%$ \\
\hline 18. Margem Bruta do Leite $(\mathrm{R} \$)(7-9)$ & $119.377,12$ & $123.868,90$ & $186.433,93$ & $117.582,64$ \\
\hline 19. Margem Bruta unitária $(\mathrm{R} \$)(18 \div 1)$ & 0,1727 & 0,2447 & 0,2007 & 0,2112 \\
\hline 20. Margem Líquida do Leite $(\mathrm{R} \$)(7$ - 10) & $87.481,75$ & $84.444,79$ & $146.828,49$ & $84.238,06$ \\
\hline 21. Margem Líquida unitária $(\mathrm{R} \$)(20 \div 1)$ & 0,1265 & 0,1668 & 0,1581 & 0,1513 \\
\hline 22. Lucro Total $(\mathrm{R} \$)(7-11)$ & $54.944,20$ & $53.915,71$ & $110.514,98$ & $55.861,42$ \\
\hline 23. Lucro Unitário $(\mathrm{R} \$)(22 \div 1)$ & 0,0795 & 0,1065 & 0,1190 & 0,1003 \\
\hline 24. Estoque de Capital (sem terra) (R\$) & $438.596,00$ & $422.840,00$ & $591.773,98$ & $500.915,00$ \\
\hline 25. Tx remuneração capital sem terra $(20 \div 24)$ & $19,94 \%$ & $19,97 \%$ & $24,81 \%$ & $16,81 \%$ \\
\hline
\end{tabular}


Aspecto relevante a ser considerado, é que, comparando com a propriedade $\mathrm{B}$, que possui um rebanho mais rústico, a propriedade $\mathrm{A}$, mais tecnificada, gasta muito mais em diversos setores da criação, como sanidade, reprodução, fornecimento de concentrados, cria e recria de novilhas. Assim, nesse ano, observou-se que a rentabilidade de quem aplica mais em tecnologia foi inferior. Resultados semelhantes foram obtidos por Lopes et al. (2005).

Com a redução nas margens de lucro, o proprietário tem que estar atento à relação custo/benefício das práticas tecnológicas que adota, e buscar uma alternativa para melhorar essa relação. No caso da Fazenda A, o sistema de produção mais especializado é o mais adequado nessa propriedade, que possui um rebanho já formado, infraestrutura adequada, funcionários treinados e apoio técnico e uma taxa de retorno expressiva. A alternativa tomada, naquele momento, foi aumentar a produção de leite, através do contínuo melhoramento no manejo e manutenção das novilhas na propriedade.

A partir de 2004, percebe-se que a tecnificação da empresa A, propiciou que a mesma tivesse um aumento de produção de $34,37 \%$, com uma pequena variação no seu rebanho e mesmo gasto proporcional de concentrado e mão-de-obra de 2003. Com esse aumento de produção e conseqüentemente a diluição dos custos fixos, houve um acréscimo de $25 \%$ de margem líquida unitária, um aumento de $101 \%$ no lucro total da empresa e um acréscimo de $24 \%$ na taxa de retorno sobre o capital investido sem terra, passando de $19,94 \%$ a $24,81 \%$.

A propriedade $\mathrm{B}$, teve um problema imprevisível com a silagem, que dobrou o valor de seu custo, passando de R \$ 15.126,87 (2003), para R \$ 31.881,77 (2004), com pequena variação na produção. Além do aumento do custo total, esse problema tornou-se um entrave para o aumento de produção, já que não tinha trato suficiente para o rebanho.

Ressalta-se que são vários os fatores que devem ser analisados para uma tomada de decisão. Os resultados das propriedades mostram que a Fazenda B era mais eficiente que a Fazenda A, no ano de 2003. Esses resultados poderiam fazer concluir que um sistema é melhor que o outro, e substituir o sistema de produção por um semelhante a da propriedade B. Por isso, na tomada de decisão, devem-se analisar os resultados num período mais longo, no mínimo dois períodos, e considerar os eventos previsíveis e imprevisíveis que ocorreram. O sistema de produção mais tecnificado da propriedade $\mathrm{A}$, permitiu que a propriedade tivesse uma resposta melhor às técnicas implementadas e aumentasse sua escala de produção, diluindo o custo unitário, aumentando a margem líquida unitária, o lucro total e a taxa de retorno sobre o capital, tornando-se mais eficiente e mais lucrativa que a propriedade B no ano de 2004.

Pôde-se concluir que o aumento de escala de produção diluiu-se os custos fixos da atividade, diminuindo o custo total e aumentando as margens; o uso de tecnologias viáveis permite uma melhor resposta do sistema a diversos fatores de produção, permitindo uma adaptação mais rápida do sistema, ajustando os fatores e influenciando no retorno financeiro; o custo de produção da Fazenda B foi menor que da Fazenda A, não sendo, no entanto, possível comparar propriedades sob o ponto de vista de qual é o melhor sistema, pois os fatores de produção são diferentes.

\section{REFERÊNCIAS BIBLIOGRÁFICAS}

BRAVO-URETA, B. E.; RIEGER, L. Dairy farm efficieny measurement using stochastic frontiers and neoclassical duality. American al of Agricultural Economics, [S.l.], v. 73, n. 2, p. 421-426, 1991.

BUENO, P. R. B. de; RORATO, P. R. N.; DÜRR, J. W.; KRUG, E. N. B. Valor econômico para componentes do leite no estado do Rio Grande do Sul. Revista Brasileira de Zootecnia, Viçosa, v. 33, n. 6, p. 2256-2265, 2004. Suplement 3.

GOMES, S. T. Economia da produção do leite. Belo Horizonte: [s.n.], 2000.

GOMES, S. T.; CASTRO, M. C. D.; TAVARES, M. S. Análise da influência da produtividade do rebanho no custo de produção de leite. Coronel Pacheco: CNPGL, 1989. 4 p. Comunicado técnico.

KUMBHAKAR, S. C.; BISWAS, B.; BAILEY, D. V. A study of economic efficiency of Utah dairy farmers: a system approach. The Review of Economics and Statistics, v. 71, n. 4, p. 595-604, 1989.

LOPES, M. A.; CARVALHO, F. de M. Custo de produção do leite. Lavras: UFLA, 2000. 42 p. (Boletim agropecuário, 33).

LOPES, M. A.; LIMA, A. L. R.; CARVALHO, F. de M.; REIS, R. P.; SANTOS, I. C.; SARAIVA, F. H. Controle gerencial e estudo da rentabilidade de sistemas de produção de leite na região de Lavras (MG). Revista Ciência e Agrotecnologia, Lavras, v. 28, n. 4, p. 883-892, 2004a. 
LOPES, M. A.; LIMA, A. L. R.; CARVALHO, F. de M.; REIS, R. P.; SANTOS, I. C.; SARAIVA, F. H. Controle gerencial e estudo da rentabilidade de sistemas de produção de leite na região de Lavras (MG). Revista Ciência e Agrotecnologia, Lavras, v. 28, n. 4, p. 883-892, 2004b.

LOPES, M. A.; LIMA, A. L. R.; CARVALHO, F. de M.; REIS, R. P.; SANTOS, I. C.; SARAIVA, F. H.

Resultados econômicos de sistemas de produção de leite com diferentes níveis tecnólogicos na região de Lavras (MG). Arquivo Brasileiro de Medicina

Veterinária e Zootecnia, Belo Horizonte, v. 57, n. 4, p. 485-493, 2005.

MADALENA, F. E. Valores econômicos para a seleção de gordura e proteína do leite. Revista
Brasileira de Zootecnia, Viçosa, v. 29, n. 3, p. 678$684,2000$.

MARTINS, G. A.; MADALENA, F. H.; BRUSCHI, J. H.; COSTA, J. L. da; MONTEIRO, J. B. N. Objetivos econômicos de seleção de bovinos de leite para fazenda demonstrativa na Zona da Mata de Minas Gerais.

Revista Brasileira de Zootecnia, Viçosa, v. 32, n. 2, p. 304-314, 2003.

REIS, R. P.; MEDEIROS, A. L.; MONTEIRO, L. A. Custos de produção da atividade leiteira na região sul de Minas Gerais. Organizações Rurais e Agroindustriais, Lavras, v. 3, n. 2, p. 45-52, 2001 .

TUPY, O.; YAMAGUCHI, L. C. T. Identificando benchmarks de leite. Revista de Economia e Sociologia Rural, Brasília, v. 40, n. 1, p. 81-96, 2002. 